\title{
Herança da resistência a Watermelon mosaic virus em melancia ${ }^{1}$
}

\author{
Lindomar Maria da Silveira², Manoel Abilio de Queiróz $z^{3}$, José Abérsio de Araújo Lima4, \\ Glauber Henrique de Sousa Nunes ${ }^{2}$, Aline Kelly Queiroz do Nascimento ${ }^{5}$, Izaías da Silva Lima Neto
}

http://dx.doi.org/10.1590/0034-737X201461040012

\begin{abstract}
RESUMO
Entre as doenças que ocorrem na cultura da melancia (Citrullus lanatus), a virose ocasionada por Watermelon mosaic virus (WMV) se destaca entre as principais, sendo a resistência genética a forma mais indicada de controle. Dessa forma, é importante o conhecimento do controle genético da resistência que se pretende trabalhar. Objetivando estudar a herança da resistência ao WMV em melancia, foram realizados cruzamentos entre o cultivar Crimson Sweet (CS) suscetível e a linha L26 resistente. Populações segregantes e não segregantes obtidas dos cruzamentos foram inoculadas com um isolado de WMV e avaliadas quanto ao aparecimento de sintomas e à presença do vírus por testes de ELISA indireto contra antissoro específico para WMV. A hipótese de herança monogênica foi avaliada em diferentes graus médios de dominância e pelo método da máxima verossimilhança. Foram obtidas variâncias genética $\left(\sigma_{\mathrm{G}}^{2}\right)$, ambiental $\left(\sigma_{\mathrm{E}}^{2}\right)$, fenotípica $\left(\sigma_{\mathrm{F} 2}^{2}\right)$, aditiva $\left(\sigma_{\mathrm{A}}^{2}\right)$ e de dominância $\left(\sigma_{\mathrm{D}}^{2}\right)$, herdabilidades nos sentidos amplo $\left(\mathrm{h}_{\mathrm{a}}^{2}\right)$ e restrito $\left(\mathrm{h}_{\mathrm{r}}^{2}\right)$. A herança monogênica foi rejeitada. $\mathrm{O}$ grau médio de dominância indicou efeito de dominância completa. As herdabilidades no sentido amplo foram baixas; portanto, constatou-se que o controle da resistência a WMV nas populações de melancia estudadas é do tipo oligogênica, com presença de efeitos aditivos e não aditivos e presença de genes maiores e poligenes.
\end{abstract}

Palavras-chave: Citrullus lanatus, controle genético, WMV, Potyvirus.

\section{ABSTRACT}

\section{Inheritance of resistance to Watermelon mosaic virus in watermelon}

Among the diseases that occur in the watermelon (Citrullus lanatus), a disease caused by Watermelon mosaic virus (WMV) is considered of great importance. Considering that genetic resistance is the best method for controlling virus diseases, it is important to know the genetic inheritance for each virus resistance. Aiming to study the inheritance of resistance to WMV in watermelon, crosses were made between Crimson Sweet (CS) and the resistant line L26. Segregants and non-segregants plant populations were inoculated with an isolate of WMV. The inoculated plants were evaluated by indirect ELISA with antiserum for WMV and symptomatology in the inoculated plants, according to a previously established graded scale. The hypothesis of monogenic inheritance was tested under different presumed average degrees of dominance as well as using the maximum likelihood. The estimated variances of the populations were used to obtain the genetic $\left(\sigma_{\mathrm{G}}^{2}\right)$ the environmental $\left(\sigma_{\mathrm{E}}^{2}\right)$, phenotypic $\left(\sigma_{\mathrm{F} 2}^{2}\right)$, additive $\left(\sigma_{\mathrm{A}}^{2}\right)$ and dominance $\left(\sigma_{\mathrm{D}}^{2}\right)$ variances as well as the broad $\left(\mathrm{h}_{\mathrm{a}}^{2}\right)$ and narrow sense $\left(\mathrm{h}_{\mathrm{r}}^{2}\right)$ heritabilities. The monogenic inheritance was rejected. The

\footnotetext{
Recebido para publicação em 26/06/2012 e aprovado em 14/08/2013.

${ }^{1}$ Este trabalho é parte da tese de doutorado da primeira autora.

${ }^{2}$ Engenheiros-Agrônomos, Doutores. Departamento de Ciências Vegetais, Universidade Federal Rural do Semi-Árido, Avenida Francisco Mota, 572, Bairro Costa e Silva, 59625900, Mossoró, Rio Grande do Norte, Brasil. lindomarmaria@yahoo.com.br (autora para correspondência); glauber@ufersa.edu.br

${ }^{3}$ Engenheiro-Agrônomo, Ph.D. Departamento de Tecnologia e Ciências Sociais, Universidade do Estado da Bahia, Avenida Doutor Chastinet Guimarães, s/n, Bairro São Geraldo, 48900-000, Juazeiro, Bahia, Brasil. manoelabiliomaq@gmail.com

${ }^{4}$ Engenheiro-Agrônomo, Ph.D. Departamento de Fitotecnia, Universidade Federal do Ceará, Campus do Pici, Bloco 805, 60940-900, Fortaleza, Ceará, Brasil. albersio@ufc.br ${ }^{5}$ Engenheira-Agrônoma, Doutora. Departamento de Fitotecnia, Universidade Federal do Ceará, Campus do Pici, Bloco 805, 60940-900, Fortaleza, Ceará, Brasil. alynekellly@yahoo.com.br

${ }^{6}$ Engenheiro-Agrônomo, Doutor. Curso de Engenharia Agronômica, Universidade Federal do Vale do São Francisco, Rodovia BR 407, KM 12, Lote 543 PSNC, s/nº C1, 56300-990, Petrolina, Pernambuco, Brasil. izaias.limaneto@univasf.edu.br
} 
estimation of the average degree of dominance indicated complete dominance. The broad sense heritability was low for the two variables analyzed. Therefore, the genetic control of resistance to WMV in the watermelon populations analyzed showed to be oligogenic, with the presence of additive and non additive effects as well as the presence of major genes and polygenes.

Key words: Citrullus lanatus, genetic control, WMV.

\section{INTRODUÇÃO}

Entre as cucurbitáceas de importância econômica no Brasil, a melancia [Citrullus lanatus (Thunb.) Matsum \& Nakai] se destaca, estando entre as cinco hortaliças mais importantes. Em 2010 as principais regiões produtoras foram Nordeste e Sul, com 701.213 e 505.782 toneladas, respectivamente (IBGE, 2010). Porém, os principais cultivares disponíveis no comércio são importados, de modo que quando cultivados no Brasil apresentam suscetibilidade a diferentes pragas e patógenos, em virtude de terem sido desenvolvidos para condições diferentes daquelas prevalecentes nas regiões de cultivo no Brasil. Entre as principais viroses destacam-se aquelas ocasionadas pelos vírus da família Potyviridae, gênero Potyvirus: Papaya ringspot virus, type watermelon (PRSV-W), Watermelon mosaic virus (WMV) e Zucchini yellow mosaic virus - ZYMV) (Desbiez \& Lecoq, 1997; Purcifull et al., 1984a; Purcifull et al., 1984b; Oliveira et al., 2000, 2002).

Os vírus do gênero Potyvirus são transmitidos de maneira não persistente ou não circulativa por várias espécies de afídeos, o que dificulta seu controle pelo uso de produtos químicos para o controle dos vetores (Ramos et $a l .$, 2003). Por essa razão, a resistência genética constitui o método mais indicado para reduzir os danos ocasionados por esses vírus. Fontes de resistência a PRSV-W, WMV e ZYMV têm sido identificadas em várias espécies de cucurbitáceas, incluindo Citrullus sp. (Oliveira et al., 2002), Cucumis sativus L. (Silva \& Costa, 1978), C. colocynthis L. (Provvidenti, 1986) e Cucurbita moschata (Svoboda \& Polák, 2004).

Por outro lado, o controle genético da resistência aos vírus do gênero Potyvirus pode variar de acordo com a fonte de resistência. Para resistência a WMV, há relatos de controle monogênico dominante em meloeiro (Cucumis melo L.) (Gilbert et al., 1994), resistência controlada por dois genes recessivos em melancia (Sittolin et al., 2000, Xu et al., 2004) e controle poligênico também em melancia (Beserra Júnior et al., 2006). O conhecimento da herança genética da resistência pode permitir o desenvolvimento de estratégias que possibilitem sua transferência em programas de melhoramento para resistência a viroses de forma mais rápida e eficiente.
Diante dessas considerações, o presente trabalho teve como objetivo estudar o controle genético da resistência a WMV na linha de melancia L26 do programa de melhoramento de melancia da Embrapa Semiárido/UNEB.

\section{MATERIAL E MÉTODOS}

Foram utilizados como parentais o cultivar Crimson Sweet (CS) suscetível $\left(\mathrm{P}_{1}\right)$ e a linha de melancia L26 resistente $\left(\mathrm{P}_{2}\right)$ ao WMV (Silveira, 2008), obtida por meio de autofecundações do acesso resistente PI 244019. As populações $\mathrm{F}_{1}, \mathrm{~F}_{2}, \mathrm{RC}_{11}$ e $\mathrm{RC}_{21}$ foram obtidas no Campo Experimental do Departamento de Tecnologia e Ciências Sociais da Universidade do Estado da Bahia (UNEB/DTCS), onde foram utilizadas parcelas compostas por no mínimo 15 plantas, dispostas em fileiras contínuas. As parcelas foram alocadas uma ao lado da outra para facilitar a transferência de pólen quando dos cruzamentos. Os genitores CS e L26 foram submetidos a polinizações controladas, sendo realizados cruzamentos entre elas para obtenção das populações $F_{1}$. Posteriormente, foram obtidas as populações $\mathrm{F}_{2}$ por meio de autofecundação de $\mathrm{F}_{1} \mathrm{e}$, simultaneamente, $\mathrm{RC}_{11}$ e $\mathrm{RC}_{21}$ por cruzamentos de plantas $\mathrm{F}_{1}$ com os parentais suscetível e resistente, respectivamente. Considerando que para obtenção das populações $\mathrm{F}_{1}, \mathrm{~F}_{2}$, $\mathrm{RC}_{11}$ e $\mathrm{RC}_{21}$ utilizaram-se parcelas constituídas por pelo menos 15 plantas, para a avaliação das populações em condições controladas realizou-se a composição de amostras de cada população. Para tanto, utilizou-se número igual de sementes de cada progênie obtida em cada população.

As populações foram avaliadas em casa de vegetação no Laboratório de Virologia Vegetal da Universidade Federal do Ceará (LabVVeg/UFC). Foi utilizado delineamento em blocos casualizados com quatro repetições. Cada bloco foi constituído de 15 plantas da população $\mathrm{P}_{1}(\mathrm{CS})$, 15 de $\mathrm{P}_{2}$ (L26), 21 de $\mathrm{F}_{1}$ (CS x L26), $63 \mathrm{de} \mathrm{F}_{2}\left(\mathrm{~F}_{1} \times \mathrm{F}_{1}\right), 35$ plantas de $\mathrm{RC}_{11}\left(\mathrm{~F}_{1} \times \mathrm{CS}\right)$ e 35 plantas de $\mathrm{RC}_{21}\left(\mathrm{~F}_{1} \times \mathrm{L} 26\right.$. Sementes das populações foram semeadas em vasos contendo substrato composto de solo e esterco de curral na proporção de duas partes de solo e uma de esterco. O substrato foi esterilizado em autoclave a uma temperatura de $120{ }^{\circ} \mathrm{C}$ por $2 \mathrm{~h}$. Para cada bloco foram utilizados quatro vasos para cada um dos pais, seis vasos para $F_{1}, 16$ vasos 
para $\mathrm{F}_{2}$ e nove vasos para cada um dos RC. Foram cultivadas quatro plantas por vaso, e para cada população um dos vasos foi cultivado com apenas três plantas.

Utilizou-se como inóculo um isolado de WMV obtido em campo de produção de melão e melancia do Estado do Ceará, o qual é mantido no Banco Ativo de Vírus do LabVVeg/UFC (Oliveira et al., 2000). A primeira inoculação foi realizada nas folhas cotiledonares das plantas antes do surgimento da primeira folha definitiva. Utilizou-se como fonte de inóculo extrato de plantas de abobrinha (Cucurbita pepo L.) cv. Caserta sistemicamente infectadas por WMV. Plantas de abobrinha também foram utilizadas como testemunha suscetível, sendo inoculadas quando da inoculação das populações. As amostras foliares para avaliações por 'Enzyme-linked immunosorbent assay' (ELISA) indireto foram coletadas em vários pontos das plantas. Os extratos foram preparados na presença de solução tampão Fosfato de potássio $0,5 \mathrm{M}$ e pH 7,5, por meio da maceração de tecido foliar infectado na proporção de 1,0 g de tecido foliar infectado para 2,0 mL de solução. As amostras para as análises por ELISA indireto foram preparadas nas mesmas condições, usando-se iguais quantidades de 1,0 g de tecido das plantas, diluídas nas mesmas proporções com o tampão das amostras (1:2), a fim de possibilitar avaliações qualitativas quanto à presença do vírus nas plantas inoculadas e estimativas semiquantitativas da presença do vírus nas plantas inoculadas (Almeida, 2001). Todas as plantas inoculadas de todos os cruzamentos e cultivares, inclusive aquelas usadas como controle (abobrinha Caserta), foram avaliadas dessa forma, usando $1,0 \mathrm{~g}$ de tecido foliar de cada planta macerado na presença de 2,0 mL de tampão de extração.

Após a primeira inoculação foi realizada avaliação visual da incidência de plantas com sintomas, tendo a avaliação sintomatológica sido realizada 10 dias após a primeira inoculação, onde se adotou a escala de notas previamente estabelecida: 1 : sem sintomas; 2 : mosaico com ou sem clareamento das nervuras e/ou enrolamento do limbo; 3: mosaico, enrolamento do limbo, necrose das brotações e/ou bolhosidade; e 4: mosaico, enrolamento do limbo, necrose das brotações, bolhosidade e/ou deformação severa. Após a avaliação sintomatológica, as plantas foram testadas individualmente por ELISA indireto contra antissoro específico para WMV, usando-se as mesmas proporções prumencionadas.

De acordo com Almeida (2001), uma planta foi considerada de resultado negativo em ELISA quando apresentou absorbância inferior a duas vezes a média das absorbâncias das plantas sadias (plantas sem inoculação utilizadas como controle) mais duas vezes o desvio padrão das leituras para as plantas sadias. As plantas que não apresentaram sintomas e foram negativas em ELISA foram submetidas a uma segunda inoculação para dimi- nuir a possibilidade de escape. Vinte dias após a segunda inoculação, foi realizada nova avaliação sintomatológica seguida de sorologia por ELISA indireto, para confirmação da resistência das plantas que não apresentaram sintomas e foram negativas no primeiro teste. As plantas que não apresentaram sintomas mesmo após a segunda inoculação, mas tiveram valores de absorbância (ABS) em ELISA indireto 2,5 acima da média das absorbâncias das plantas sadias, foram consideradas tolerantes. Os efeitos aditivos [a] e não aditivos [d] do(s) gene(s) que controla $(\mathrm{m})$ o caráter foram estimados a partir das médias, variâncias e número de plantas das seis gerações pelo método dos quadrados mínimos ponderados (Mather \& Jinks, 1984; Ramalho et al., 1993). As análises foram realizadas utilizando o programa estatístico Genes (Cruz, 2006). Os dados foram usados para testar a hipótese de herança monogênica em diferentes graus médios de dominância presumidos, como descrito por Oliveira et al. (2003).

A hipótese de herança monogênica e/ou a presença de locos poligênicos ou modificadores afetando o caráter foi testada pela metodologia proposta por Silva (2003), utilizando-se estimadores de máxima verossimilhança. Essa metodologia considera modelos onde o modelo mais geral considera a presença de um gene de efeito maior e poligenes com efeitos aditivos e de dominância, além de variâncias ambientais iguais em todas as gerações. Também foram admitidos genes independentes, de efeito maior, bem como poligenes, tendo a partir das funções de verossimilhança para cada modelo sido possível compor testes de interesse considerando as várias hipóteses (Silva, 2003).

\section{RESULTADOS E DISCUSSÃO}

A distribuição de frequência para reação ao WMV avaliada por sintomas (NS) e por sorolgia (ABS) foi semelhante quando considerados $\mathrm{P}_{1}$ e $\mathrm{P}_{2}$, tendo as duas populações apresentado plantas resistentes e suscetíveis, porém $\mathrm{P}_{2}$ teve maior proporção de plantas suscetíveis (Figura 1). A frequência de plantas resistentes em L26 foi de $74 \%$ e em Crimson Sweet 58\%, com os resultados confirmados por ELISA (Figura 1).

Quando consideradas as populações $\mathrm{F}_{1}, \mathrm{~F}_{2}, \mathrm{RC}_{1}$ e $\mathrm{RC}_{2}$, foi observada diferença nas distribuições das avaliações, exceto para $\mathrm{P}_{1}$, que apresentou maior proporção de plantas com nota 1 quando considerada NS (Figura 1). Mesmo com os dois pais segregando para resistência e suscetibilidade, quando observada a distribuição de frequência de fenótipos nas populações segregantes, bem como para a população $\mathrm{F}_{1}$, a distribuição diferiu de uma baseada em herança monogênica, permitindo inferir que a herança da resistência a WMV em L26 seja oligo ou poligênica. 

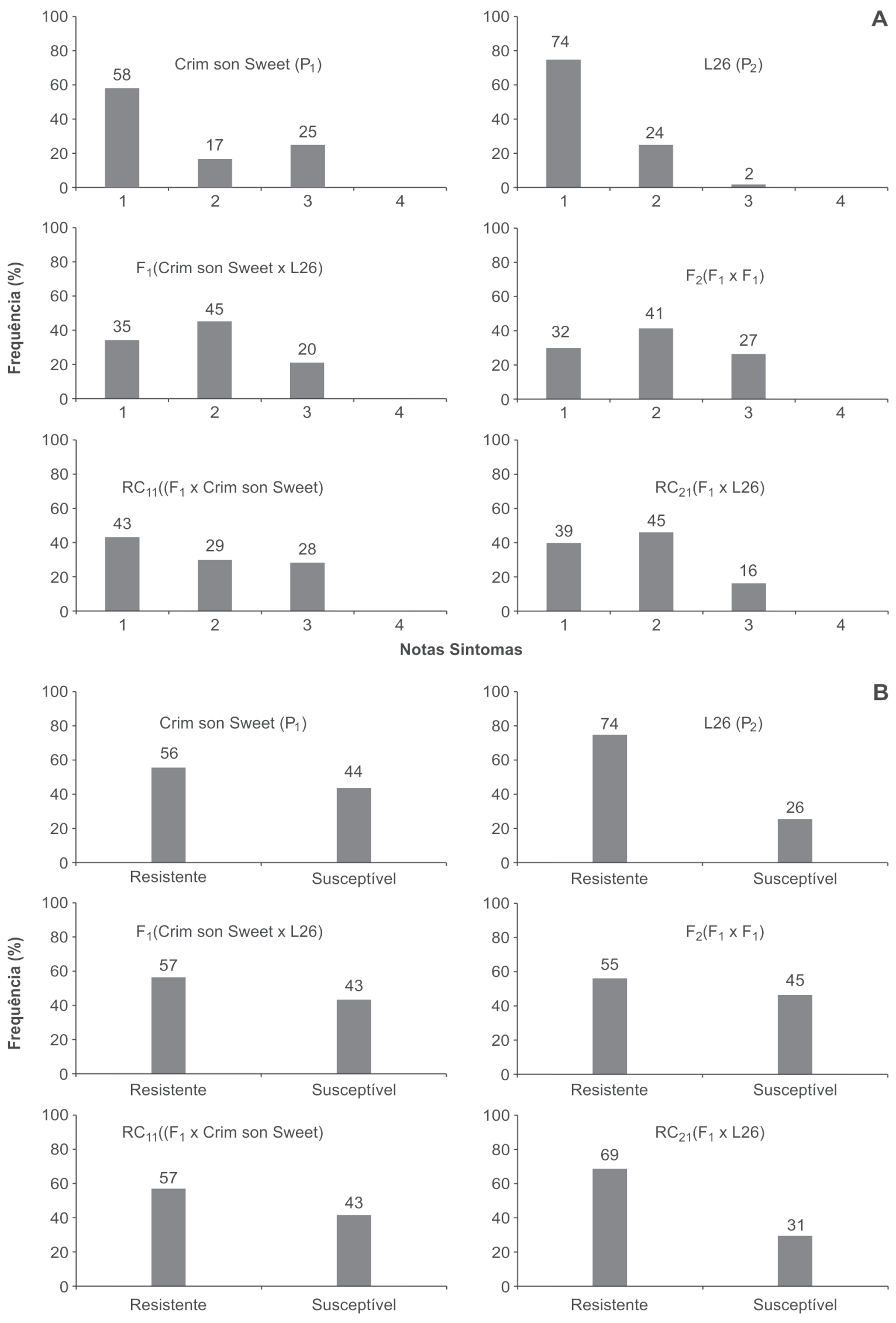

Sorologia em ELISA indireto (Absorbâncias)

Figura 1. Distribuição de frequências para reação de genótipos de melancia (Citrullus spp.) a Watermelon mosaic virus (WMV), referentes a notas de sintomas (A) e absorbância em ELISA (B). UFERSA, Mossoró (RN), 2008. 
Mesmo que uma análise geral das distribuições de frequências dos fenótipos das populações para as variáveis NS e ABS levasse à conclusão de que a característica de resistência a WMV em L26 não é controlada monogenicamente, observa-se que a expressão dos sintomas nessas populações ocorreu de forma pouco severa, de modo que a maioria das plantas suscetíveis foi classificada com notas 2 e 3 para NS, e, excetuando-se $\mathrm{P}_{1}$, as demais populações apresentaram a maior proporção de plantas suscetíveis na classe de nota 2.

A ocorrência de plantas tolerantes em 'Crimson Sweet' em razão dos valores de ABS não deve constituir escape, uma vez que as plantas sofreram duas inoculações, e as testemunhas utilizadas nas inoculações foram todas suscetíveis quando avaliadas por sintomas (NS) e por ELISA indireto. De outra parte, a alta porcentagem de plantas tolerantes em 'Crimson Sweet' pode ser explicada pelo fato de que as sementes utilizadas no presente estudo foram obtidas por meio de autofecundações, o que pode ter contribuído para formação de combinações gênicas diferentes. Tais resultados demonstram a importância do uso da sorologia para comprovar a replicação do vírus nas plantas, mesmo sem essas apresentarem sintomas evidentes da infecção, caracterizando o comportamento de tolerância.

Vale salientar que a expressão de sintomas ocasionados pela infecção por vírus é bastante influenciada pelas condições ambientais e pelo hospedeiro infectado, e além da influência ambiental, alguns genótipos podem ser tolerantes e não expressarem sintomas quando infectados.

As estimativas do qui-quadrado $\left(\chi^{2}\right)$ referentes ao teste de herança monogênica não foram significativas $(\mathrm{P} \leq$ $0,05)$ para todos os graus médios de dominância presumidos em ambas as variáveis (Figura 2), levando a rejeição da hipótese de herança monogênica e indicando ser a resistência a WMV em L26 controlada por mais de um gene.

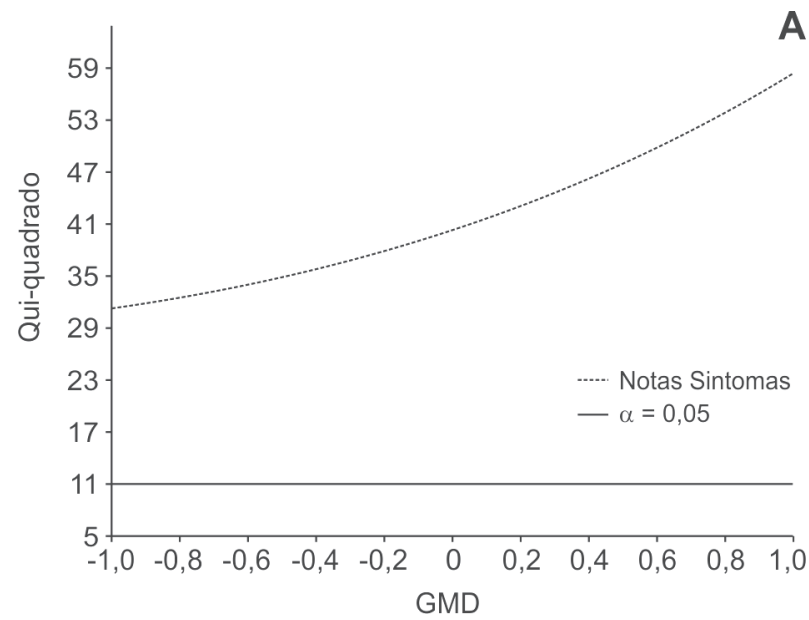

Gilbert-Albertini et al. (1993) relataram a herança da resistência a WMV em Cucurbita moschata Duch. como sendo controlada por um gene recessivo, resultado semelhante ao descrito por Gilbert et al. (1994) para o controle genético da resistência a WMV em meloeiro. Para melancia, Sittolin et al. (2000) relataram a resistência a WMV na introdução BT-8501 como sendo controlada por dois pares de genes recessivos, enquanto Beserra Júnior et al. (2006), avaliando a resistência a WMV na introdução de melancia PI 595202, relataram o controle genético como sendo oligo ou poligênico, com o número de genes estimado em 2,61. Dessa forma, evidencia-se a necessidade de se investigar o tipo de herança nas fontes que se deseja utilizar em programas de melhoramento, uma vez que os resultados já encontrados não podem ser extrapolados, visto que o controle genético da característica de resistência pode variar de acordo com o genótipo que apresenta essa resistência.

O $\chi^{2}$ estimado entre as médias esperadas e observadas não foi significativo para nenhuma das variáveis consideradas (Tabela 1), indicando que o modelo aditivo-dominante é adequado para explicar o controle da resistência em L26, não sendo necessária a inclusão de interações epistáticas no modelo. O componente aditivo [a] foi menor que o não aditivo [d] apenas para a variável NS. As estimativas do GMD em NS indicam sobre dominância, enquanto para ABS estão próximos de um, com indicação de dominância completa (Tabela 1), possivelmente por conta de plantas que não apresentaram sintomas, mas permitiram a replicação do vírus. As médias de $\mathrm{F}_{1}$ nas duas variáveis aproximam-se das de 'Crimson Sweet', indicando que existe dominância dos alelos que conferem suscetibilidade em relação aos que conferem resistência (Tabela 1).

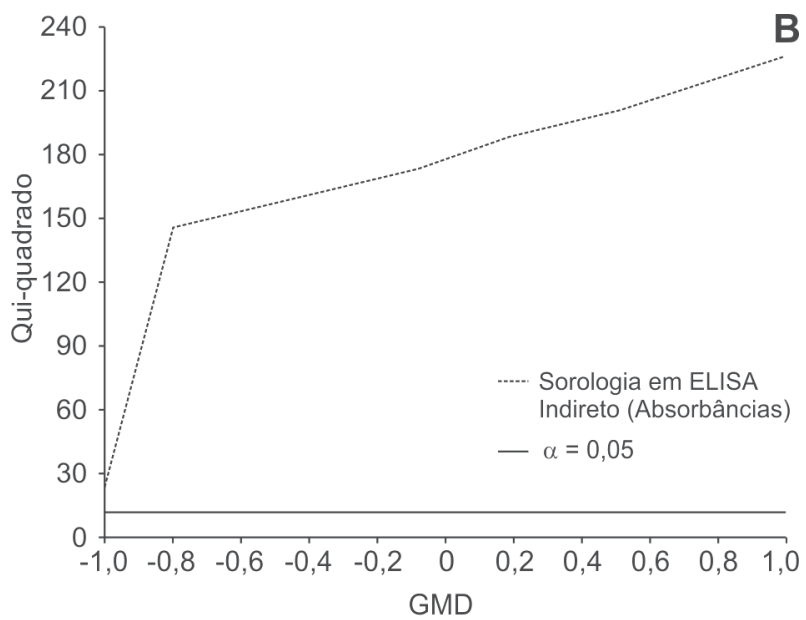

Figura 2. Valores de qui-quadrado observados para teste de hipótese de herança monogênica em diferentes graus médios de dominância presumidos, para reação de genótipos de melancia (Citrullus spp.) ao Watermelon mosaic virus (WMV), considerando as variáveis notas de sintomas (A) e sorologia (B). UFERSA, Mossoró (RN), 2008. 
As estimativas de herdabilidade no sentido amplo também não apresentaram consistência para as variáveis com valores de 13,69 e 6,69 para NS e ABS, respectivamente (Tabela 2). Devido à ocorrência de variâncias negativas, a herdabilidade no sentido restrito para NS não foi calculada, porém os valores de herdabilidade no sentido amplo para ABS foi 34,04 (Tabela 2). O valor de herdabilidade no sentido amplo observado neste estudo difere daquele relatado por Beserra Júnior et al. (2006), que encontraram elevada herdabilidade no sentido amplo para resistência a WMV em melancia $(0,80)$. A herdabilidade não é apenas uma propriedade do caráter, mas também da população e das condições ambientais a que foram submetidos os indivíduos da população (Ramalho et al., 1993). Considerando que as estimativas das herdabilidades foram baseadas em variâncias e que os erros das estimativas de variâncias são normalmente altos, é importante usar de cautela quando se utilizarem esses parâmetros (Ramalho et al., 1993). Assim, os baixos valores de herdabilidade observados para resistência a WMV não impossibilitam a seleção de plantas resistentes em populações segregantes obtidas do cruzamento de L26 e 'Crimson Sweet'.

Os dados encontrados com a análise das duas variáveis mostraram que ocorreu variação nos parâmetros estimados nas condições em que foram avaliados, de modo que o resultado final foi alterado de acordo com a variável analisada. Dessa forma, com base nos dados apresentados (Tabelas 1 e 2), pode-se inferir que, dependendo da interação

Tabela 1. Médias de populações de melancia (Citrullus spp.) $\mathrm{P}_{1}$, $\mathrm{P}_{2}, \mathrm{~F}_{1}, \mathrm{~F}_{2}, \mathrm{RC}_{11}, \mathrm{RC}_{21}$ e componentes de média para reação ao Watermelon mosaic virus (WMV). UFERSA, Mossoró (RN), 2008

\begin{tabular}{lcc}
\hline $\begin{array}{l}\text { Populações de } \\
\text { melancia } \\
\text { (Citrullus spp.) }\end{array}$ & $\begin{array}{c}\text { Notas } \\
\text { de sintomas }\end{array}$ & $\begin{array}{c}\text { ELISA indireto } \\
\text { (absorbâncias) }\end{array}$ \\
\cline { 2 - 3 } $\mathrm{CS}\left(\mathrm{P}_{1}\right)$ & 1,667 & 1,663 \\
$\mathrm{~L} 26\left(\mathrm{P}_{2}\right)$ & 1,278 & 1,019 \\
$\mathrm{~F}_{1}$ & 1,855 & 1,647 \\
$\mathrm{~F}_{2}$ & 1,942 & 1,628 \\
$\mathrm{RC}_{11}\left(\mathrm{~F}_{1} \times \mathrm{CS}\right)$ & 1,843 & 1,529 \\
$\mathrm{RC}_{21}\left(\mathrm{~F}_{1} \times \mathrm{L} 26\right)$ & 1,769 & 1,054 \\
\hline $\mathrm{m}$ & $1,5740(0,0356)^{1}$ & $1,3213(0,2554)$ \\
{$[\mathrm{a}]$} & $0,2079(0,0342)$ & $0,3944(0,0736)$ \\
{$[\mathrm{d}]$} & $0,4784(0,0649)$ & $0,2583(0,1503)$ \\
$\chi^{2}$ & $0,0462^{\mathrm{NS}}$ & 0,0755 NS \\
$\mathrm{GMD}$ & 1,9689 & 0,9505 \\
$N$ & $*$ & 2,07 \\
\hline
\end{tabular}

$\mathrm{m}=$ média estimada dos parentais $\mathrm{P}_{1}$ e $\mathrm{P}_{2} ;[\mathrm{a}]=$ efeito gênico aditivo; $[\mathrm{d}]=$ efeito gênico não aditivo; $\chi^{2}=$ Qui-quadrado para teste do modelo aditivo-dominante; GMD = Grau médio de dominância; e $n=$ número de genes.

${ }^{1}$ Valores entre parêntesis representam o erro padrão; NS = não significativo; * não calculado devido à ocorrência de estimativas negativas de variâncias. patógeno-hospedeiro, o uso de sintomatologia sem a avaliação da presença do vírus por técnicas sorológicas ou moleculares pode levar a interpretações equivocadas, de modo a comprometer o processo de seleção de fontes de resistência. Considerando que a expressão de sintomas ocasionados pela infecção por WMV é altamente influenciada pelas condições ambientes, além da caracterização sintomatológica, sugere-se que a avaliação por sorologia seja utilizada em programas de melhoramento que busque a seleção de fontes de resistência a esse vírus.

O teste de máxima verossimilhança (Silva, 2003) trabalha com modelos hierarquizados, de forma que o contraste do Modelo 1 com o Modelo 5, que confronta a existência de gene com efeito maior mais poligenes, com apenas poligenes, permite que se rejeite $\mathrm{H}_{0}$. Dessa forma, há evidência da existência de um gene de efeito maior (Tabela 3). Assim, comparando o Modelo 1 com o Modelo 7, que confronta a existência de um gene de efeito maior mais poligenes, com apenas gene de efeito maior, $\mathrm{H}_{0}$ é rejeitado, de forma que também há evidência de efeitos poligênicos (Tabela 3). Desse modo, o modelo mais adequado para explicar a herança da resistência a WMV em L26 é aquele que considera a existência de um gene maior com efeitos aditivos e de dominância, juntamente com poligenes. No entanto, essa metodologia não testa a existência de mais de um gene maior. Por outro lado, os dados obtidos pelo teste de máxima verossimilhança concordam com o teste de herança monogênica em que o teste de herança monogênica simples foi rejeitado.

Tabela 2. Variâncias de populações de melancia (Citrullus spp.) $\mathrm{P}_{1}, \mathrm{P}_{2}, \mathrm{~F}_{1}, \mathrm{~F}_{2}, \mathrm{RC}_{11}, \mathrm{RC}_{21}$, e herdabilidade no sentido amplo para reação ao Watermelon mosaic virus (WMV). UFERSA, Mossoró (RN), 2008

\begin{tabular}{|c|c|c|}
\hline \multirow{2}{*}{$\begin{array}{l}\text { Populações de } \\
\text { melancia } \\
\text { (Citrullus spp.) }\end{array}$} & \multicolumn{2}{|c|}{ Varâncias } \\
\hline & $\begin{array}{c}\text { Notas } \\
\text { de } \text { sintomas }\end{array}$ & $\begin{array}{l}\text { ELISA indireto } \\
\text { (absorbâncias) }\end{array}$ \\
\hline $\mathrm{CS}\left(\mathrm{P}_{1}\right)$ & 0,7430 & 2,7800 \\
\hline L26 $\left(\mathrm{P}_{2}\right)$ & 0,2420 & 2,1680 \\
\hline $\mathrm{F}_{1}$ & 0,5380 & 2,8790 \\
\hline $\mathrm{F}_{2}$ & 0,5880 & 2,7960 \\
\hline $\mathrm{RC}_{11}\left(\mathrm{~F}_{1} \times \mathrm{CS}\right)$ & 0,6890 & 2,5950 \\
\hline $\mathrm{RC}_{21}\left(\mathrm{~F}_{1} \times \mathrm{L} 26\right)$ & 0,4960 & 2,0440 \\
\hline$\sigma_{\mathrm{E}}^{2}$ & 0,5878 & 2,7957 \\
\hline$\sigma_{G}^{2}$ & 0,0802 & 0,1870 \\
\hline$\sigma_{A}^{2}$ & $-0,0097$ & 0,9518 \\
\hline$\sigma_{D}^{2}$ & 0,0900 & $-0,7647$ \\
\hline $\mathrm{h}_{\mathrm{r}}^{2}$ & $*$ & 34,04 \\
\hline$h^{2}{ }_{a}$ & 13,69 & 6,69 \\
\hline \multicolumn{3}{|c|}{$\begin{array}{l}\sigma_{\mathrm{E}}^{2}=\text { variância ambiental; } \sigma_{\mathrm{G}}^{2}=\text { variância genética; } \sigma_{\mathrm{A}}^{2}=\text { variância } \\
\text { devida aos efeitos aditivos; } \sigma_{\mathrm{D}}^{2}=\text { variância devida aos efeitos de } \\
\text { dominância; } \mathrm{h}_{\mathrm{r}}^{2}=\text { herdabilidade no sentido restrito; } \mathrm{h}_{\mathrm{a}}^{2}=\text { herdabilidade } \\
\text { no sentido amplo; } * \text { não calculado devido a estimativas negativas de } \\
\text { variância aditiva. }\end{array}$} \\
\hline
\end{tabular}


Tabela 3. Testes de hipótese de herança monogênica por meio da função de máxima verossimilhança para resistência ao Watermelon mosaic virus (WMV) em melancia (Citrullus spp.). UFERSA, Mossoró (RN), 2008

\begin{tabular}{|c|c|c|c|c|c|}
\hline \multirow{2}{*}{ Modelos } & \multirow{2}{*}{$\begin{array}{l}\text { Graus de } \\
\text { liberdade }\end{array}$} & \multicolumn{2}{|c|}{ Notas de sintomas } & \multicolumn{2}{|c|}{ ELISA indireto (absorbâncias) } \\
\hline & & $\mathbf{X}^{2}$ & Prob. & $\mathbf{X}^{2}$ & Prob. \\
\hline 1 vs. 2 & 3 & 21,2721 & 0,000092 & 203,0252 & 0,000000 \\
\hline 1 vs. 3 & 1 & 21,1422 & 0,000004 & 200,1701 & 0,000000 \\
\hline 1 vs. 4 & 4 & 41,1634 & 0,000000 & 203,0305 & 0,000000 \\
\hline 1 vs. 5 & 2 & 23,8306 & 0,000006 & 202,0150 & 0,000000 \\
\hline 1 vs. 6 & 5 & 41,1634 & 0,000000 & 204,8034 & 0,000000 \\
\hline 1 vs. 7 & 5 & 29,6596 & 0,000017 & 204,4377 & 0,000000 \\
\hline 1 vs. 8 & 6 & 41,3978 & 0,000000 & 204,9749 & 0,000000 \\
\hline 1 vs. 9 & 7 & 50,7326 & 0,000000 & 214,7009 & 0,000000 \\
\hline 2 vs. 4 & 1 & 19,8913 & 0,000008 & 0,0053 & 0,941866 \\
\hline 2 vs. 6 & 2 & 19,8913 & 0,000048 & 1,7782 & 0,411032 \\
\hline 2 vs. 7 & 2 & 8,38753 & 0,015090 & 1,4125 & 0,493489 \\
\hline 2 vs. 8 & 3 & 20,1257 & 0,000160 & 1,9497 & 0,582917 \\
\hline 2 vs. 9 & 4 & 29,4605 & 0,000006 & 11,6757 & 0,019933 \\
\hline 3 vs. 5 & 1 & 2,68835 & 0,101084 & 1,8449 & 0,174375 \\
\hline 3 vs. 6 & 4 & 20,0212 & 0,000494 & 4,6333 & 0,327035 \\
\hline 3 vs. 8 & 5 & 20,2555 & 0,001119 & 4,8048 & 0,440165 \\
\hline 3 vs. 9 & 6 & 29,5904 & 0,000047 & 14,5308 & 0,024237 \\
\hline 4 vs. 6 & 1 & 0,0000 & 0,999824 & 1,7728 & 0,183030 \\
\hline 4 vs. 8 & 2 & 0,2344 & 0,889396 & 1,9444 & 0,378258 \\
\hline 4 vs. 9 & 3 & 9,5692 & 0,022606 & 11,6704 & 0,008602 \\
\hline 5 vs. 6 & 3 & 17,3328 & 0,000603 & 2,7884 & 0,425420 \\
\hline 5 vs. 9 & 5 & 26,9020 & 0,000059 & 12,6859 & 0,026507 \\
\hline 6 vs. 9 & 2 & 9,5692 & 0,008357 & 9,8975 & 0,007092 \\
\hline 7 vs. 8 & 1 & 11,7382 & 0,000612 & 0,5372 & 0,463610 \\
\hline 7 vs. 9 & 2 & 21,0730 & 0,000026 & 10,2632 & 0,005907 \\
\hline 8 vs. 9 & 1 & 21,2721 & 0,000003 & 203,0252 & 0,000000 \\
\hline
\end{tabular}

\section{CONCLUSÃO}

O controle da resistência a WMV nas populações de melancia estudadas é do tipo oligogênica, com presença de efeitos aditivos e não aditivos e presença de genes maiores e poligenes.

\section{REFERÊNCIAS}

Almeida AMR (2001) Detecção e quantificação de vírus pelo teste de Elisa. In: Almeida AMR \& Lima JAA (Eds.) Princípios e técnicas de diagnose aplicadas a fitovirologia. Londrina, EMBRAPA Soja. p.63-94.

Beserra Júnior JEA, Maluf WR, Figueira AR \& Barguil BM (2006) Herança da resistência ao Watermelon mosaic virus em melancia (C. lanantus L.). Fitopatologia Brasileira, 32:302-305.

Cruz CD (2006) Programa Genes: biometria. Viçosa, Editora UFV. $382 \mathrm{p}$.

Desbiez C \& Lecoq H (1997) Zucchini yellow mosaic virus. Plant Pathology, 46:809-829.

Gilbert RZ, Kyle MM \& Munger HM (1994) Inheritance of resistance watermelon mosaic virus in Cucumis melo $\mathrm{L}$. HortScience, 29:107-194.

Gilbert-Albertini F, Lecoq H, Pitrat M \& Nicoler JL (1993) Resistance of Cucurbita moschata to watermelon mosaic virus type 2 and its genetic relation to resistance to zucchini yellow mosaic virus. Euphytica, 3:231-237.
IBGE - Instituto Brasileiro de Geografia e Estatísitica (2010) Estados: lavoura temporária 2010. Disponível em: <http// w w w. i b g e. g o v. b r / e s t a d o s a t / temas.php?sigla=ba\&tema=lavouratemporária2010>. Acessado em: 12 de janeiro de 2012.

Mather K \& Jinks JL (1984) Introdução a genética biométrica. Ribeirão Preto, Sociedade Brasileira de Genética. 242p.

Oliveira ACB, Maluf WR, Pinto JEBP \& Azevedo SM (2003) Resistance to papaya ringspot virus in Cucurbita pepo $\mathrm{L}$. introgressed from a interspecific C. pepo x C. moschata cross. Euphytica, 132:211-215.

Oliveira VB, Lima JAA, Vale CC \& Paiva WO (2000) Caracterização biológica e sorológica de isolados de potyvirus obtidos de cucurbitáceas no Nordeste brasileiro. Fitopatologia Brasileira, 18:628-636.

Oliveira VB, Queiróz MA \& Lima AA (2002) Fontes de resistência aos principais potyvirus isolados de cucurbitáceas no Nordeste brasileiro. Horticultura Brasileira, 20:589-592.

Provvidenti R (1986) Reactions of accessions of Citrullus colocynthis from Nigéria to Zucchini yellow mosaic virus and other cucurbit viruses. Cucurbit Genetic Cooperative Report, 9:82-83.

Purcifull D, Hiebert E \& Edwardson J (1984a) Watermelon mosaic virus 2. Kew, England, CMI/ABB. 7p. (Descriptions of plant viruses $\left.n^{\circ} 293\right)$.

Purcifull DJ, Edwardson J, Hiebert E \& Gonsalves D (1984b) Watermelon mosaic 1 potyvirus. Kew, England, CMI/AAB. 5p (Descriptions of plant viruses $n^{\circ} 292$ ). 
Ramalho MAP, Santos JB \& Zimmermann MJO (1993) Genética quantitativa em plantas autógamas. Goiânia, UFG. 271p.

Ramos NF, Lima JAA \& Gonçalves MFB (2003) Efeitos da interação de potyvirus em híbridos de meloeiro, variedades de melancia e abobrinha. Fitopatologia Brasileira, 28:199-204.

Silva N \& Costa CP (1978) Triagem de cultivares e híbridos de pepino (Cucumis sativus L.) para resistência a WMV-1 (Watermelon mosaic virus-1). Summa Phytopathologica, 4:71-75.

Silva WP (2003) Estimadores de máxima verossimilhança em misturas de densidades normais: Uma aplicação em genética Dissertação de Mestrado. Universidade Federal de Lavras, Lavras. $60 \mathrm{p}$.

Silveira LM (2008) Levantamento sorológico de vírus em cucurbitáceas na região do Submédio São Francisco e determinação de fontes e herança de resistência em melancia a espécies de potyvírus. Tese de doutorado. Universidade Federal Rural do Semi-Árido, Mossoró. 129p.
Sittolin IM, Pavan MA \& Silva N (2000) Herança da tolerância de melancia aos vírus do mosaico amarelo da abobrinha-de-moita e do mosaico da melancia-2. Summa Phytophalogica, 26:210214.

Svoboda J \& Polák J (2004) Preliminary evaluation of squash cultivars for resistance to a Czech isolate of zucchini yellow mosaic virus. In: 8th EUCARPIA Meeting on Cucurbit Genetics and Breeding, Olomouc. Proceedings, Palacky University Olomouc. p. 231-235.

Xu Y, Kang D, Shi Z, Shen H \& Wehner T (2004) Inheritance of resistance to zucchini yellow mosaic virus and watermelon mosaic virus in watermelon. Journal of Heredity, 95:498-502. 